\title{
Comparison between Hybrid, Reverse Hybrid, and Non-Bismuth Levofloxacin Quadruple Regimens for Helicobacter Pylori Infection in Egypt: A Randomized Trial
}

\author{
Ayman Fathy El Sayed ${ }^{1}$, Ayman Magd Eldin Mohammad Sadek ${ }^{2}$, Walid Ahmed Ragab Abdelhamid 3,*
}

1. Lecturer of Internal Medicine, Faculty of Human Medicine, Zagazig University, Zagazig, Egypt

2. Assistant Professor of Internal Medicine, Faculty of Human Medicine, Zagazig University, Zagazig, Egypt

3. Lecturer of Internal Medicine, Faculty of Human Medicine, Zagazig University, Zagazig, Egypt

\footnotetext{
* Corresponding Author:
}

Walid Ahmed Ragab Abdelhamid, MD Lecturer of Internal Medicine, Faculty of Human Medicine, Zagazig University, Zagazig, Egypt

Tel: + 201062904443

Fax: + 20552345452

Email: WAAbdelHamid@medicine. zu.edu.eg

Received: 18 Nov. 2020

Accepted: 15 Apr. 2021

\section{ABSTRACT}

\section{BACKGROUND}

The prevalence of Helicobacter pylori (H. pylori) in developing countries is $50.8 \%$, with the highest occurrence presented in Africa (79.1\%). It increases the risk of chronic gastritis, peptic ulcer, cancer of the stomach, and lymphoma. The effect of standard treatment for $H$. pylori eradication is below $80 \%$, and evaluation of alternative lines of treatment is needed. We aimed to compare the hybrid, reverse hybrid, and levofloxacin quadruple therapies as first-line therapy in Egypt.

\section{METHODS}

This was a randomized interventional trial done in the clinics affiliated with the Internal Medicine Department. 330 individuals were selected according to the inclusion criteria. They were divided into three groups: group 1 (110 subjects who received a reverse hybrid regimen), group 2 (110 subjects who received a hybrid regimen), and group 3 (110 subjects who received a non-bismuth levofloxacin quadruple regimen).

\section{RESULTS}

Group 3 had a significantly lower eradication rate of $82.7 \%$ versus $92.7 \%$ and $91.8 \%$ in groups 1 and 2, respectively. There were non-significant differences in the incidence rates of adverse events among the three groups.

\section{CONCLUSION}

Both the reverse hybrid and hybrid groups had good eradication rates in the Egyptian population, but non-bismuth levofloxacin quadruple therapy did not obtain a sufficient eradication rate.

\section{KEYWORDS:}

Peptic ulcer, Eradication, Helicobacter pylori, Levofloxacin, Omeprazole, Nitazoxanide, Doxycycline

\section{Please cite this paper as:}

Fathy El Sayed A, Magd Eldin Mohammad Sadek A, Ahmed Ragab Abdelhamid W. Comparison between Hybrid, Reverse Hybrid, and Non-Bismuth Levofloxacin Quadruple Regimens for Helicobacter Pylori Infection in Egypt: A Randomized Trial. Middle East J Dig Dis 2021;13:222-228. doi: 10.34172/mejdd.2021.229.

\section{INTRODUCTION}

The frequency of infection by Helicobacter pylori (H. pylori) in developing countries is high despite its lower prevalence worldwide. ${ }^{1} H$. pylori prevalence 
in developing countries is $50.8 \%$, with being prominent in Africa (79.1\%). ${ }^{2,3}$ Unfortunately, details about the extent of this issue in Egypt are still scarce.

The significance of $H$. pylori infection is related to its strong correlation with chronic gastritis, peptic ulcer, adenocarcinoma of the stomach, and gastric mucosaassociated lymphoid tissue lymphoma. ${ }^{4}$

Invasive diagnostic methods for $H$. pylori infection are the most accurate, but they are cumbersome and costly. On the other hand, there are easier and cheaper non-invasive tests, particularly the $H$. pylori stool antigen and urea breath test..$^{5}$ The development of resistant strains to antibiotics, particularly clarithromycin, has reduced response to standard triple therapy (STT) $(<80 \%)$, thus requiring alternative better treatment options with higher safety and compliance. ${ }^{6}$

The treatment option using bismuth-based quadruple treatment gained popularity as an alternative to clarithromycinbased treatment, ${ }^{7}$ but it is not a practical option in countries with unavailable bismuth and/or tetracycline. ${ }^{8}$ In addition, bismuth-based treatment is more complex and has less safety. ${ }^{9}$ This leads to the need for research on other treatment options such as sequential and concomitant non-bismuth (clarithromycin based) quadruple treatments. ${ }^{10}$

A new combined sequential and concomitant therapy named hybrid therapy (HT) has been developed, which is cheaper and more efficient. ${ }^{11}$ On the other hand, the obstacle in this therapy is the patients' compliance, as they need to start two additional drugs in the second week of the treatment, causing less adherence to treatment. Thus, a newer therapy called reverse hybrid therapy (RHT) has developed a better understanding of the sequence (quadruple-dual). ${ }^{12}$

An additional alternative option to bismuth-based therapy is levofloxacin quadruple therapy, which is less sophisticated and less harmful than bismuth-based therapy. It includes levofloxacin, omeprazole, nitazoxanide, and doxycycline (LOND), which has a favorable outcome. ${ }^{13,14}$

We aimed to estimate the effectiveness of HT, RHT, and LOND as first-line therapy in the Egyptian population and to find out the most satisfactory and the highest adherence rate regimen in the Egyptians.

\section{MATERIALS AND METHODS}

We conducted an open-label interventional randomized trial. We allocated the participants attending the clinic to stratified randomization method. The randomization was stratified randomization using a computer over the three treatment groups, as illustrated in the flowchart diagram (figure 1).

Figure 1 shows the selection method of the participants in the study from the patients attending the clinic by simple randomization over the three treatment groups. ITT $=$ intention to treat; $\mathrm{PP}=$ Per protocol; $\mathrm{RHT}=$ Reverse hybrid therapy; $\mathrm{HT}=$ hybrid therapy; LOND = Levofloxacin-omeprazolenitazoxanide-doxycycline.

The sample size was 330 participants, using OPEN EPI (www.OpenEpi.com, updated 2013/04/06. Emory University, Rollins School of Public Health, Atlanta, Georgia, USA) at power: $80 \%$ and C.I: $95 \%$. We carried out this research after taking informed written consent from the participants after the approval of the Ethics Committee. We followed the code of ethics for research on humans according to the Declaration of Helsinki guidelines. The study was approved by the Ethics Committee of the Faculty of Medicine, Zagazig University, under the Institutional Review Board number 5089-9-1-2019. We registered the study in the ClinicalTrials. gov with ID number NCT04039412.

We included participants aged 18 years or more, of both sexes, with no history of previous treatment for $H$. pylori. We excluded participants with known hypersensitivity to drugs used in the regimens and those with a history of recent antibiotic use in the previous 3 months. After taking the medical history of the participants and performing a complete clinical examination, we used the fecal antigen test (FAT) to identify $H$. pylori antigen by enzyme immunosorbent assay. The participants with positive FAT were considered for eradication therapy if aged over 45 years with dyspepsia, or age under 45 years with peptic ulcer disease or with dyspepsia and any other risk factors (loss of weight, repeated vomiting, gastric bleeding, or familial history of gastric cancer). Participants were randomly allocated to three treatment groups. Group 1 of 110 participants who received RHT in the form of clarithromycin $500 \mathrm{mg}$ twice daily, omeprazole $20 \mathrm{mg}$ twice daily, amoxicillin $1 \mathrm{~g}$ twice daily, and metronidazole $500 \mathrm{mg}$ thrice daily 


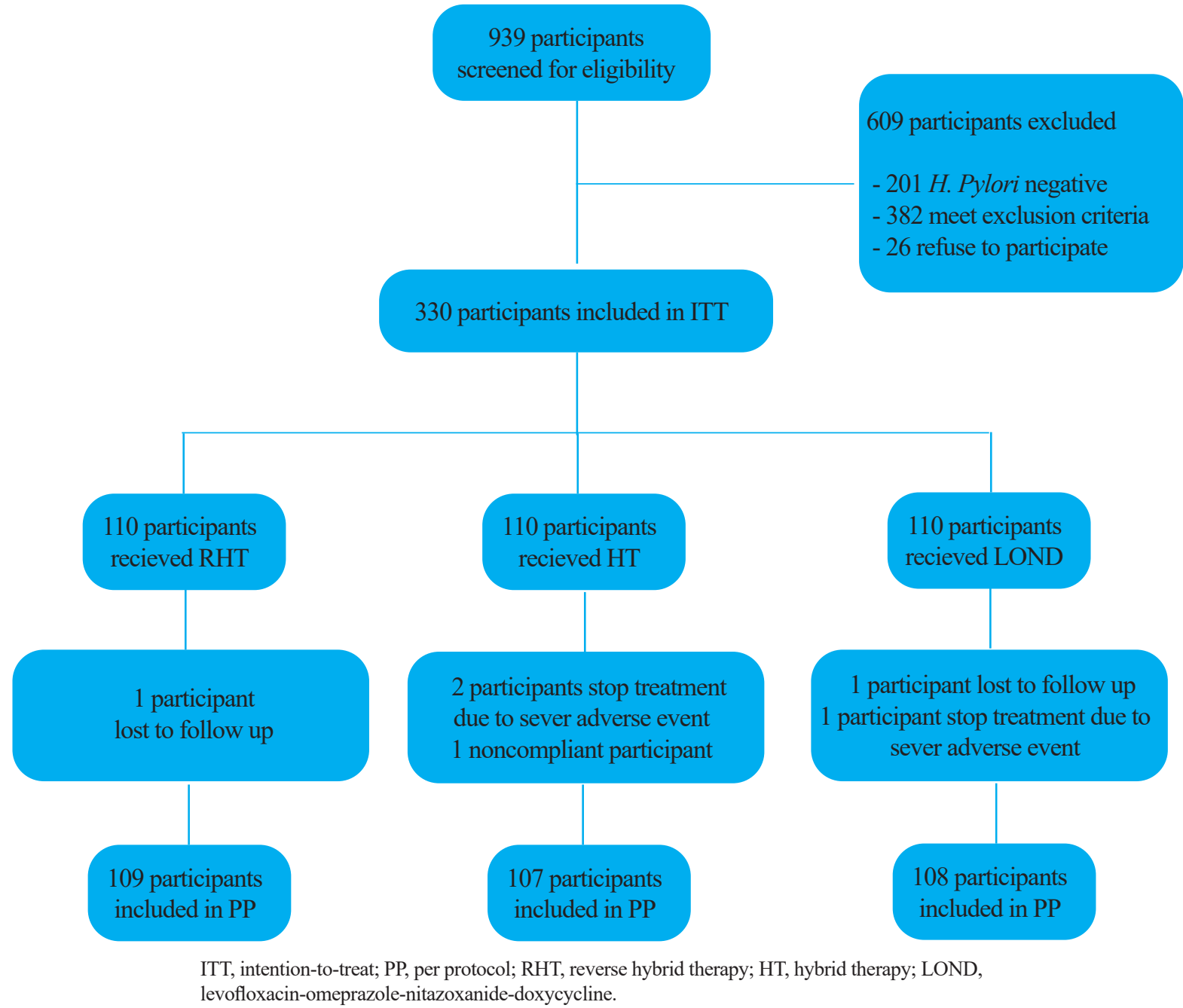

Fig.1: Study participants' flowchart

for 1 week, followed by omeprazole $20 \mathrm{mg}$ twice daily, and amoxicillin $1 \mathrm{~g}$ twice daily in the 2 nd week. Group 2 of 110 patients who received HT in the form of omeprazole $20 \mathrm{mg}$ twice daily, and amoxicillin $1 \mathrm{~g}$ twice daily in the 1st week, then clarithromycin $500 \mathrm{mg}$ twice daily, omeprazole $20 \mathrm{mg}$ twice daily, amoxicillin $1 \mathrm{~g}$ twice daily, and metronidazole $500 \mathrm{mg}$ thrice daily in the 2nd week. Group 3 of 110 patients who received LOND in the form of levofloxacin $250 \mathrm{mg}$ once daily, omeprazole $40 \mathrm{mg}$ once daily, nitazoxanide $500 \mathrm{mg}$ twice daily, and doxycycline $100 \mathrm{mg}$ once daily for 10 days. We followed up on the drug compliance and the occurrence of adverse events after one week and at the end of treatment. We divided the severity of adverse events according to the presence or absence. If it was present, we would subdivide it further, accord- ing to the extent of daily activity limitation, into mild, moderate, and severe (no limitation, partial limitation, and profound limitation, respectively). We retested by the FAT one month after finishing the treatment and 14 days after discontinuing the proton pump inhibitors.

\section{Statistical analysis}

We used IBM SPSS Statistics for Windows, Version 19.0 (Released 2010, IBM Corp, Armonk, NY). Data were expressed in the form of number and percentage for categorical variables and mean \pm standard deviation (SD) for continuous variables that were tested for normality by Shapiro-Wilk test and revealed a normal distribution. Categorical data were analyzed by the Kruskal-Wallis $\mathrm{H}$ test, and if results were significant, post hoc analysis by 
Table 1: Comparison of the three groups regarding demographic and clinical data

\begin{tabular}{|c|c|c|c|c|c|}
\hline Characteristics & Group 1 & Group 2 & Group 3 & Test & Sig. \\
\hline Age (years) (Mean \pm SD) & $32.05 \pm 9.772$ & $32.31 \pm 9.409$ & $32.44 \pm 9.713$ & 0.045 & 0.956 \\
\hline $\begin{array}{l}\text { Sex: no (\%) } \\
\text {-Male } \\
\text {-Female }\end{array}$ & $\begin{array}{l}53(48.2) \\
57(51.8)\end{array}$ & $\begin{array}{l}52(47.3) \\
58(52.7)\end{array}$ & $\begin{array}{l}55(50) \\
55(50)\end{array}$ & 0.169 & 0.919 \\
\hline Smoking: no (\%) & $35(31.8)$ & $34(30.9)$ & $32(29.1)$ & 0.199 & 0.905 \\
\hline $\begin{array}{l}\text { Caffeine intake: no (\%) } \\
\text {-None } \\
\text {-Tea } \\
\text {-Coffee } \\
\text {-Tea and coffee }\end{array}$ & $\begin{array}{l}29(26.4) \\
46(41.8) \\
13(11.8) \\
22(20)\end{array}$ & $\begin{array}{l}38(34.5) \\
40(36.4) \\
16(14.5) \\
16(14.5)\end{array}$ & $\begin{array}{c}39(35.5) \\
47(42.7) \\
11(10) \\
13(11.8)\end{array}$ & 3.722 & 0.155 \\
\hline NSAID intake: no (\%) & $23(20.9)$ & $20(18.2)$ & $20(18.2)$ & 0.352 & 0.839 \\
\hline $\begin{array}{l}\text { Comorbidity: no (\%) } \\
\text {-None } \\
\text {-Diabetic } \\
\text {-Hypertensive } \\
\text {-Both }\end{array}$ & $\begin{array}{l}94(85.5) \\
7(6.4) \\
6(5.5) \\
3(2.7)\end{array}$ & $\begin{array}{l}88(80) \\
10(9.1) \\
7(6.4) \\
5(4.5) \\
\end{array}$ & $\begin{array}{c}85(77.3) \\
10(9.1) \\
11(10) \\
4(3.6)\end{array}$ & 2.462 & 0.292 \\
\hline GIT bleeding: no (\%) & $5(4.5)$ & $4(3.6)$ & $5(4.5)$ & 0.149 & 0.928 \\
\hline $\operatorname{BMI}\left(\mathrm{kg} / \mathrm{m}^{2}\right)($ Mean $\pm \mathrm{SD})$ & $27.45 \pm 4.609$ & $26.72 \pm 4.282$ & $27.29 \pm 4.265$ & 0.854 & 0.426 \\
\hline $\begin{array}{l}\text { BMI groups: no (\%) } \\
\text {-Normal } \\
\text {-Overweight } \\
\text {-Obese }\end{array}$ & $\begin{array}{l}30(27.3) \\
42(38.2) \\
38(34.5)\end{array}$ & $\begin{array}{c}37(33.6) \\
40(36.4) \\
33(30)\end{array}$ & $\begin{array}{l}32(29.1) \\
36(32.7) \\
42(38.2)\end{array}$ & 1.632 & 0.442 \\
\hline
\end{tabular}

(Sig): Significance, (NSAID): Non-steroidal anti-inflammatory drugs, (GIT): Gastrointestinal tract, and (BMI): Body mass index.

Table 2: Comparison of the three groups regarding outcomes of treatment

\begin{tabular}{|c|c|c|c|c|c|}
\hline Analysis & Group 1 & Group 2 & Group 3 & Test & $p$-value \\
\hline \multicolumn{6}{|c|}{ Eradication: n (\%) } \\
\hline ITT & $102(92.7 \%)$ & $101(91.8 \%)$ & $91(82.7 \%)$ & 6.662 & $0.036^{*}$ \\
\hline $95 \% \mathrm{CI}$ & $86.2 \%$ to $96.8 \%$ & $85 \%$ to $96.2 \%$ & $74.3 \%$ to $89.3 \%$ & & \\
\hline $\mathrm{PP}$ & $102(93.6 \%)$ & $101(94.4 \%)$ & $91(84.3 \%)$ & 8.118 & $0.017 *$ \\
\hline $95 \%$ CI & $87.2 \%$ to $97.4 \%$ & $88.2 \%$ to $97.9 \%$ & $76 \%$ to $90.6 \%$ & & \\
\hline \multicolumn{6}{|c|}{ The severity of adverse events: $n$} \\
\hline & $61(55.5)$ & $52(47.3)$ & $65(59.1)$ & & \\
\hline -None & $33(30)$ & $28(25.5$ & $35(31.8)$ & & \\
\hline -Mild & $16(14.5)$ & $28(25.5)$ & $9(8.2)$ & 7.055 & 0.029 \\
\hline $\begin{array}{l}\text {-Moderate } \\
\text {-Severe }\end{array}$ & $0(0)$ & $2(1.8)$ & $1(0.9)$ & & \\
\hline
\end{tabular}

(ITT): Intention-to-treat, (PP): Per protocol, (CI): Confidence interval.

the Mann-Whitney test was done. Continuous data were inspected by one-way analysis of variance (ANOVA). A two-sided $(\alpha=2) p$ value of less than 0.05 was considered significant.

\section{RESULTS}

Our subjects were 160 men and 170 women with ages ranging from 18 to 56 years. All demographic and clinical data presented in table 1 showed non-significant differences between the three groups.

Group 3 had a significantly lower eradication rate of $82.7 \%$ (91 of 110 ) versus $92.7 \%$ (102 of 110 ), and $91.8 \%$
(101 of 110) in groups 1 and 2, respectively ( $p=0.036$ ). The post hoc analysis revealed that the main difference was found between groups 1 and group 3 ( $p=0.025)$, in addition to group 2 and group $3(p=0.049)$. The severity of adverse reactions was significantly different between the three groups $(p=0.023)$, and the post hoc analysis clarified that this difference was between group 2 and group 3 ( $p=0.008$, table 2 ).

The incidence rates of adverse events in the three groups are demonstrated in table 3, with a non-significant difference among the three groups. 
Table 3: Comparison of the three groups regarding adverse events of treatment.

\begin{tabular}{lccccc}
\hline Adverse events & Group 1 & Group 2 & Group 3 & Test & $p$ value \\
\hline Non: no (\%) & $61(55.5)$ & $52(47.3)$ & $66(60)$ & 3.676 & 0.159 \\
\hline Bitter taste: no (\%) & $13(11.8)$ & $11(10)$ & $6(5.5)$ & 2.851 & 0.240 \\
\hline Nausea: no (\%) & $7(6.4)$ & $10(9.1)$ & $8(7.3)$ & 0.604 & 0.739 \\
\hline Epigastric pain: no (\%) & $9(8.2)$ & $10(9.1)$ & $10(9.1)$ & 0.075 & 0.963 \\
\hline Vomiting: no (\%) & $2(1.8)$ & $4(3.6)$ & $1(0.9)$ & 2.037 & 0.361 \\
\hline Bloating: no (\%) & $2(1.8)$ & $4(3.6)$ & $5(4.5)$ & 1.313 & 0.519 \\
\hline Diarrhea: no (\%) & $8(7.3)$ & $11(10)$ & $7(6.4)$ & 1.082 & 0.582 \\
\hline Dizziness: no (\%) & $2(1.8)$ & $2(1.8)$ & $2(1.8)$ & 0.000 & 1.000 \\
\hline Fatigue: no (\%) & $6(5.5)$ & $6(5.5)$ & $5(4.5)$ & 0.124 & 0.940 \\
\hline
\end{tabular}

\section{DISCUSSION}

Cure of $H$. pylori infection principally relies on the adherence of the patient to the treatment, the duration of the antimicrobial therapy, and the occurrence of $H$. pylori resistant strains to antibiotics. ${ }^{15}$ As $H$. pylori infection is an infective illness, the optimal plan is to cure $H$. pylori infection at a rate higher than 95\%. The effectiveness of $H$. pylori therapy was categorized by Graham as $\mathrm{F}$ or unacceptable ( $80 \%$ cure rate), D or poor (81-84\%), $\mathrm{C}$ or fair (85-89\%), B or good (90-95\%), and A or excellent $(95-100 \%) .{ }^{16}$

As stated by the American College of Gastroenterology Clinical Guidelines, bismuth quadruple therapy is approved as the first-line therapy for $H$. pylori infection in the United States, and hybrid therapy is a second option. ${ }^{17}$

In the Egyptian population, different lines of treatment for $H$. pylori need to be evaluated. Our study is the first head-to-head, randomized trial to compare RHT, HT, and LOND in the Egyptian population.

The net results in the current study revealed significantly superior eradication rates in both HT and RHT (91.8\% and $92.7 \%$, respectively) versus LOND therapy $(82.7 \%)(p=0.036)$. On the contrary, LOND therapy showed significantly lower adverse events $(p=0.023)$.

Regarding age and sex distribution in our study, there were no significant differences between the three groups. In addition, there were no significant differences between the three groups regarding the history of smoking, caffeine consumption, previous non-steroidal anti-inflammatory drug intake, comorbid conditions, history of melena, and BMI.

In our study, group 3 had a significantly lower eradication rate $(82.7 \%)$. The significantly lower eradication rate in group 3 is in agreement with Branquinho and colleagues, ${ }^{18}$ and Sarkeshikian and co-workers, ${ }^{19}$ who reported an eradication rate of $79 \%$ and $78.18 \%$, respectively. On the other hand, Basu and others 13 reported an eradication rate of $88.9 \%$, and Kale-Pradhan and colleagues ${ }^{20}$ reported an eradication rate of $87.8 \%$. A probable explanation for the lower rate of $H$. pylori eradication with LOND therapy in our study is the frequent use of levofloxacin and doxycycline in Egypt for urinary tract infections, chest infections, and skin infections, which increase the risk of drug resistance.

In addition, eradication rates were significantly higher in group $1(92.7 \%)$ and group $2(91.8 \%)$. These results are in agreement with Lin and colleagues ${ }^{21}$ and MolinaInfante and others. ${ }^{22}$ Perhaps this may be caused by the synergy between amoxicillin and clarithromycin, as amoxicillin inhibits bacterial cell wall synthesis that knocks down the transmembrane efflux system. Therefore, clarithromycin accumulates inside bacteria and overwhelms the bacterial resistance mechanism. ${ }^{23}$

In our study, the severity of adverse events in group 2 was the most severe $(p=0.023)$, with three patients who could not continue treatment because of marked dizziness and repeated vomiting. The adverse events with HT are like those obtained by Sardarian and colleagues ${ }^{24}$ and Metanat and co-workers. ${ }^{25}$ However, Kefeli and colleagues ${ }^{26}$ and Wang and others ${ }^{27}$ reported fewer adverse events with HT and recommended it as first-line therapy. The high incidence of adverse events in this group may be due to the prolonged course of amoxicillin treatment and the addition of multiple antibiotics in the second week of 
treatment, though it cannot quite explain the difference between RHT and HT groups.

The most frequent adverse events in groups 1 and 2 were metallic taste $(11.8 \%$ and $10 \%$, respectively). While in group 3, 9.1\% of the patients experienced epigastric pain. Sardarian and colleagues ${ }^{24}$ and Chen and co-workers ${ }^{28}$ also reported metallic taste as a major side effect in patients receiving HT. On the other hand, De Francesco and others ${ }^{23}$ found diarrhea as the most common adverse event in the HT group.

In conclusion, we found that both RHT and HT groups had good eradication rates, but LOND therapy did not obtain enough eradication rates in the Egyptian population. However, LOND therapy had the least overall adverse reaction.

The limitations of our study were the lack of urea breath test (which is more specific than fecal antigen test) and cultures (which could give us the pattern of antibiotic resistance), due to non-availability in our locations. In addition, the lack of cost-effectiveness analysis, which is an important issue in low-income countries, can be another limitation.

\section{ACKNOWLEDGMENTS}

We thank all staff working in outpatient clinics of Internal Medicine Department in our hospital and the subjects of the study, whom our work would not have been completed without their co-operation.

\section{ETHICAL APPROVAL}

There is nothing to be declared.

\section{CONFLICT OF INTEREST}

The authors declare no conflict of interest related to this work.

\section{REFERENCES}

1. Alsulaimany FAS, Awan ZA, Almohamady AM, Koumu MI, Yaghmoor BE, Elhady SS, et al. Prevalence of $\mathrm{He}$ licobacter pylori Infection and Diagnostic Methods in the Middle East and North Africa Region. Medicina (Kaunas) 2020;56:169. doi: 10.3390/medicina56040169

2. Zamani M, Ebrahimtabar F, Zamani V, Miller WH, Alizadeh-Navaei R, Shokri-Shirvani J, et al. Systematic review with meta-analysis: the worldwide prevalence of Helicobacter pylori infection. Aliment Pharmacol Ther 2018;47:868-76. doi: 10.1111/apt.14561
3. Hooi JKY, Lai WY, Ng WK, Suen MMY, Underwood FE, Tanyingoh D, et al. Global Prevalence of Helicobacter pylori Infection: Systematic Review and Meta-Analysis. Gastroenterology 2017;153:420-9. doi: 10.1053/j.gastro.2017.04.022

4. Kusters JG, van Vliet AHM, Kuipers EJ. Pathogenesis of Helicobacter pylori Infection. Clin Microbiol Rev 2006;19:449-90. doi: 10.1128/cmr.00054-05

5. Garza-González E, Perez-Perez GI, Maldonado-Garza HJ, Bosques-Padilla FJ. A review of Helicobacter pylori diagnosis, treatment, and methods to detect eradication. World J Gastroenterol 2014;20:1438-49. doi: 10.3748/ wjg.v20.i6.1438

6. Huang YK, Wu MC, Wang SS, Kuo CH, Lee YC, Chang LL, et al. Lansoprazole-based sequential and concomitant therapy for the first-line Helicobacter pylori eradication. J Dig Dis 2012;13:232-8. doi: 10.1111/j.17512980.2012.00575.x

7. Malfertheiner P, Megraud F, O'Morain CA, Atherton J, Axon ATR, Bazzoli F, et al. Management of Helicobacter pylori infection--the Maastricht IV/ Florence Consensus Report. Gut 2012;61:646-64. doi: 10.1136/ gutjnl-2012-302084

8. Georgopoulos SD, Papastergiou V, Karatapanis S. Helicobacter pylori Eradication Therapies in the Era of Increasing Antibiotic Resistance: A Paradigm Shift to Improved Efficacy. Gastroenterol Res Pract 2012;2012:757926. doi: 10.1155/2012/757926

9. Liou JM, Fang YJ, Chen CC, Bair MJ, Chang CY, Lee $\mathrm{YC}$, et al. Concomitant, bismuth quadruple, and 14-day triple therapy in the first-line treatment of Helicobacter pylori: a multicentre, open-label, randomised trial. Lancet 2016;388:2355-65. doi: 10.1016/S0140-6736(16)31409-X

10. Malfertheiner P, Megraud F, O'Morain CA, Gisbert JP, Kuipers EJ, Axon AT, et al. Management of Helicobacter pylori infection-the Maastricht V/Florence Consensus Report. Gut 2017;66:6-30. doi: 10.1136/ gutjnl-2016-312288

11. Liatsos C, Georgopoulos SD. Helicobacter pylori best treatment approach: should a national consensus be the best consensus? Ann Gastroenterol 2017;30:704-6. doi: 10.20524/aog.2017.0183

12. Hsu PI, Tsay FW, Graham DY, Tsai TJ, Tsai KW, Kao JY, et al. Equivalent Efficacies of Reverse Hybrid and Bismuth Quadruple Therapies in Eradication of Helicobacter pylori Infection in a Randomized Controlled Trial. Clin Gastroenterol Hepatol 2018;16:1427-33. doi: 10.1016/j. cgh.2018.03.031

13. Basu PP, Rayapudi K, Pacana T, Shah NJ, Krishnaswamy $\mathrm{N}$, Flynn M. A randomized study comparing levofloxacin, omeprazole, nitazoxanide, and doxycycline versus triple therapy for the eradication of Helicobacter pylori. Am J Gastroenterol 2011;106:1970-5. doi: 10.1038/ ajg.2011.306

14. Abd-Elsalam S, Kobtan A, El-kalla F, Elkhalawany W, Nawasany SE, Saif SA, et al. A 2-week Ni- 
tazoxanide-based quadruple treatment as a rescue therapy for Helicobacter pylori eradication: A single center experience. Medicine 2016;95:e3879. doi:10.1097/ md.0000000000003879

15. Kanizaj TF, Kunac N. Helicobacter pylori: Future perspectives in therapy reflecting three decades of experience. World J Gastroenterol 2014;20:699-705. doi: 10.3748/ wjg.v20.i3.699

16. Yang JC, Lu CW, Lin CJ. Treatment of Helicobacter pylori infection: current status and future concepts. World $J$ Gastroenterol 2014;20:5283-93. doi: 10.3748/wjg. v20.i18.5283

17. Chey WD, Leontiadis GI, Howden CW, Moss SF. ACG Clinical Guideline: Treatment of Helicobacter pylori Infection. Am J Gastroenterol 2017;112:212-39. doi: 10.1038/ajg.2016.563

18. Branquinho D, Almeida N, Gregório C, Cabral JEP, Casela A, Donato MM, et al. Levofloxacin or Clarithromycinbased quadruple regimens: what is the best alternative as first-line treatment for Helicobacter pylori eradication in a country with high resistance rates for both antibiotics? BMC Gastroenterol 2017;17:31. doi: 10.1186/s12876017-0589-6

19. Sarkeshikian SS, Ghadir MR, Alemi F, Jalali SM, Hormati A, Mohammadbeigi A. Atorvastatin in combination with conventional antimicrobial treatment of Helicobacter pylori eradication: A randomized controlled clinical trial. J Gastroenterol Hepatol 2019;35:71-5. doi: 10.1111/ jgh. 14810

20. Kale-Pradhan PB, Mihaescu A, Wilhelm SM. Fluoroquinolone Sequential Therapy for Helicobacter pylori: A Meta-analysis. Pharmacotherapy 2015;35:719-30. doi: 10.1002/phar.1614

21. Lin TF, Wu DC, Tsay FW, Tsai KW, Tsai TJ, Peng NJ, et al. Reverse hybrid therapy achieves a similar eradication rate as standard hybrid therapy for Helicobacter pylori infection. J Chin Med Assoc 2020;83:233-7. doi: 10.1097/ jcma.0000000000000256

22. Molina-Infante J, Romano M, Fernandez-Bermejo M, Federico A, Gravina AG, Pozzati L, et al. Optimized Nonbismuth Quadruple Therapies Cure Most Patients With Helicobacter pylori Infection in Populations With High Rates of Antibiotic Resistance. Gastroenterology 2013;145:121-8. doi: 10.1053/j.gastro.2013.03.050

23. De Francesco V, Margiotta M, Zullo A, Hassan C, Troiani L, Burattini O, et al. Clarithromycin-Resistant Genotypes and Eradication of Helicobacter pylori. Ann Intern Med 2006;144:94-100. doi: 10.7326/0003-4819144-2-200601170-00006

24. Sardarian H, Fakheri H, Hosseini V, Taghvaei T, Maleki I, Mokhtare M. Comparison of Hybrid and Sequential Therapies for Helicobacter pylori Eradication in Iran: A Prospective Randomized Trial. Helicobacter 2012;18:12934. doi: 10.1111/hel.12017

25. Metanat HA, Valizadeh SM, Fakheri H, Maleki I, Taghvaei T, Hosseini V, et al. Comparison Between 10- and 14-Day Hybrid Regimens for Helicobacter pylori Eradication: A
Randomized Clinical Trial. Helicobacter 2015;20:299304. doi: 10.1111/hel.12202

26. Kefeli A, Başyigit S, Yeniova AO, Ozkan S, Nazligul Y. Comparison of the efficacy and safety of hybrid and sequential therapies as a first-line regimen for Helicobacter pylori infection in Turkey. Arch Med Sci 2018;14:27680. doi: 10.5114/aoms.2016.58595

27. Wang B, Wang YH, Lv ZF, Xiong HF, Wang H, Yang Y, et al. Review: Efficacy and Safety of Hybrid Therapy for Helicobacter pylori Infection: A Systematic Review and Meta-analysis. Helicobacter 2014;20:79-88. doi: $10.1111 /$ hel.12180

28. Chen KY. Hybrid vs sequential therapy for eradication of Helicobacter pylori in Taiwan: A prospective randomized trial. World J Gastroenterol 2015;21:10435-42. doi: 10.3748/wjg.v21.i36.10435 